University of Nebraska - Lincoln

DigitalCommons@University of Nebraska - Lincoln

Publications from USDA-ARS / UNL Faculty

U.S. Department of Agriculture: Agricultural

Research Service, Lincoln, Nebraska

$10-24-2006$

\title{
Heat stress risk factors of feedlot heifers
}

Tami M. Brown-Brandl

USDA-ARS U.S. Meat Animal Research Center, Tami.BrownBrandl@ARS.USDA.GOV

Roger A. Eigenberg

USDA-ARS, USMARC, Clay Center, NE, roger.eigenberg@ars.usda.gov

John A. Nienaber

USDA-ARS U.S. Meat Animal Research Center, john.nienaber@ars.usda.gov

Follow this and additional works at: https://digitalcommons.unl.edu/usdaarsfacpub

Part of the Agricultural Science Commons

Brown-Brandl, Tami M.; Eigenberg, Roger A.; and Nienaber, John A., "Heat stress risk factors of feedlot heifers" (2006). Publications from USDA-ARS / UNL Faculty. 143.

https://digitalcommons.unl.edu/usdaarsfacpub/143

This Article is brought to you for free and open access by the U.S. Department of Agriculture: Agricultural Research Service, Lincoln, Nebraska at DigitalCommons@University of Nebraska - Lincoln. It has been accepted for inclusion in Publications from USDA-ARS / UNL Faculty by an authorized administrator of DigitalCommons@University of Nebraska - Lincoln. 


\title{
Heat stress risk factors of feedlot heifers
}

\author{
T.M. Brown-Brandl ${ }^{*}$, R.A. Eigenberg, J.A. Nienaber \\ USDA-ARS U.S. Meat Animal Research Center, P.O. Box 166, Clay Center, Nebraska, USA 68933
}

Received 16 February 2006; received in revised form 19 April 2006; accepted 25 April 2006

\begin{abstract}
Heat stress in cattle results in millions of dollars in lost revenue each year due to production losses, and in extreme cases, death. Death losses are more likely to result from animals vulnerable to heat stress. A study was conducted to determine risk factors for heat stress in feedlot heifers. Over two consecutive summers, a total of 256 feedlot heifers (32/ breed/ year) of four breeds were observed. As a measure of stress, respiration rates and panting scores were taken twice daily (morning and afternoon) on a random sample of 10 heifers/ breed. Weights, condition scores, and temperament scores were taken on 28-day intervals during the experiment. Health history from birth to slaughter was available for every animal used in this study. It was found that at temperatures above $25{ }^{\circ} \mathrm{C}$, dark-hided animals were $25 \%$ more stressed than light-colored; a history of respiratory pneumonia increased stress level by $10.5 \%$; each level of fatness increased stress level by approximately $10 \%$; and excitable animals had a $3.2 \%$ higher stress level than calm animals. Not only did the stress level increase with these risk factors, but average daily gain was reduced. The Charolais cattle gained significantly more than all other breeds of cattle tested. Calm cattle gained 5\% more than excitable cattle. Finally, cattle treated for pneumonia gained approximately $8 \%$ slower than non-treated cattle. The results of this study have not only revealed heat stress risk factors of breed (color), condition score (fatness), temperament, and health history (treated or not treated for pneumonia), but have also shown the effectiveness of using respiration rate as an indicator of heat stress. (c) 2006 Elsevier B.V. All rights reserved.
\end{abstract}

Keywords: Feedlot cattle; Heat stress; Respiration rate; Pneumonia; Color

\section{Introduction}

Hot weather has negative effects on animal performance and well-being. Reductions in feed

\footnotetext{
Mention of trade names or commercial products in this article is solely for the purpose of providing specific information and does not imply recommendation or endorsement by the U.S. Department of Agriculture.

* Corresponding author. Tel.: +1 402762 4279; fax: +1 4027624273.

E-mail address: brandl@email.marc.usda.gov

(T.M. Brown-Brandl).
}

intake, growth, and efficiency are commonly reported in heat-stressed cattle (Hahn, 1999). Impacts of heat load on these production factors are quite varied, ranging from little to no effect in a brief exposure, to death of vulnerable animals during an extreme heat event (Hahn and Mader, 1997). Vulnerable animals have been described as ones with dark or black hides (Busby and Loy, 1996; Hungerford et al., 2000; Mader et al., 2001), compromised immune systems, more fat cover, and possibly highly excitable animals. 
Hungerford et al. (2000) conducted an investigation of a heat wave that killed more than 5000 head of cattle in northeastern Nebraska during the summer of 1999 to determine risk factors for heat related deaths. It was determined that cattle of greater weight and cattle on a program with no antibiotics, hormones, or feed additives were at greater risk of death. The most striking outcome of this study found that black cattle were 5.7 times more likely to die from heat stress than other colors of cattle. Little research has been conducted to determine the effect of health or temperament on the response to elevated temperatures, although studies have shown that compromised immune systems (Donovan et al., 1998; Wittum et al., 1996) and excitable cattle (Voisinet et al., 1997) can cause reduced gains in feedlot cattle.

Respiration rate has been shown to be a good indicator of thermal stress (Brown-Brandl et al., 2005b; Gaughan et al., 2000; Hahn et al., 1997). Respiration rate increases in a non-linear fashion in response to increasing ambient temperature, with a breakpoint or a threshold of between $20-25{ }^{\circ} \mathrm{C}$ (Eigenberg et al., 2002; Hahn et al., 1997). The advantages of using respiration rate are that it is readily observable in a production setting (Hahn et al., 1997), and little time lag occurs (in an outdoor setting) relative to the ambient dry-bulb temperature associated with it (Brown-Brandl et al., 2005a).

Along with respiration rate, the behavior of the animal changes as ambient temperature increases. Young and Hall (1993) listed behaviors exhibited by cattle experiencing excessive heat loads including the onset of open-mouthed, labored panting, and excessive salivation/drooling. They suggested that these behaviors are indicators of an animal failing to cope with stress. Mader and Davis (2002) used this information to develop a management tool called a panting score. The panting score uses behavior of the animal to assess its "heat stress" level; a panting score range from 0 , indicating a non-stressed animal, to 4 , describing an animal suffering from heat stress (severe open-mouthed panting, accompanied by protruding tongue and excessive salivation).

The objectives of this study were to determine if health status, breed (with differing coat colors), condition score, and temperament are risk factors for susceptibility to heat stress in feedlot heifers, and to determine if these potential risk factors (except condition score) lead to reduced performance during the summer time period.

\section{Materials and methods}

Two-hundred fifty-six feedlot heifers of four breeds (Angus, Charolais, Gelbvieh, and MARC III crossbred [Pinzgauer, Red Poll, Hereford, Angus]) from the USDA-ARS U.S. Meat Animal Research Center's (USMARC) population were selected for this study (32 heifers/ breed/ year). The study was conducted over two consecutive summers (2002 and 2003) in theUSMARC feedlot (located $9.6 \mathrm{~km}$ west and $3.2 \mathrm{~km}$ north of Clay Center, Nebraska). Angus cattle were black; MARC III were mostly dark-red (three of 64 were black, some were solid, others had white tailheads and/ or white faces); Gelbvieh were tan in color; Charolais were white. The breeds of cattle used in this experiment had hide colors that corresponded to the reported hair color (Angus - Black hair and black hide, MARC III dark-red hair and dark-red hide, Gelbvieh - tan hair and tan hide, Charolais - white hair and pink hide). Each year heifers initially weighing $393.5 \pm 45.4 \mathrm{~kg}$ were assigned to one of four adjacent pens $(64.6 \times 18.3 \mathrm{~m})$ by breed ( 32 heifers/pen). Heifers were implanted with Synovex-H (200 mg testosterone propionate and $20 \mathrm{mg}$ estradiol benzoate) approximately 40 days before the study began. Synovex-H is a growth promotant and was implanted in these animals to replicate U.S. cattle industry procedures. Heifers were then fed twice daily, before $0800 \mathrm{~h}$ and after $1300 \mathrm{~h}$, and had free access to water. Live weights, body condition scores, and temperament scores were recorded every 28 days.

Condition scores were taken on an expanded 27point scale due to the close similarity of cattle using the traditional 9-point scale (for comparison of these two systems see Table 1). For analyses purposes, condition scores were predicted on a daily basis by linearly interpolating between 28-day readings, and then categorizing into one of four condition score (CS) categories ([6] $\mathrm{CS}<18.5$; [7] $18.5 \leq \mathrm{CS}<21.5$; [8] $21.5 \leq \mathrm{CS}<24.5$; [9] CS $\geq 24.5$ ).

Two observers, working independently, assigned a temperament score to each animal (Table 2), based on the heifers behavior in the enclosed scale. The two observers' temperament scores were averaged to yield a single temperament score per weigh date. To 
Table 1

Comparison of standard 9-point visual body condition scores scale and an expanded 27-point visual body condition scores scale

\begin{tabular}{|c|c|c|}
\hline 9-point Scale & 27-point Scale & Description $^{\mathrm{a}}$ \\
\hline 1 & $1-3$ & Extremely thin, all skeletal structures are visible \\
\hline 2 & $4-6$ & Very thin. Skeletal structures are visible \\
\hline 3 & $7-9$ & Thin. Muscle tissue is evident, but not abundant \\
\hline 4 & $10-12$ & Marginal, ribcage backbone junction becoming less visible \\
\hline 5 & $13-15$ & $\begin{array}{l}\text { Muscle tissue is nearing maximum, fat deposit behind shoulder is noticeable, } \\
\text { ribs are covered slightly }\end{array}$ \\
\hline 6 & $16-18$ & $\begin{array}{l}\text { Muscle tissue volume is at a maximum, fat deposit behind shoulder is obvious, } \\
\text { ribs are covered completely with fat beginning to cover rump }\end{array}$ \\
\hline 7 & $19-21$ & $\begin{array}{l}\text { Fat deposits behind shoulder and at tailhead are obvious, flat appearance is } \\
\text { beginning to dominate topline }\end{array}$ \\
\hline 8 & $22-24$ & Fat deposits are flattening rump, fat is filling brisket and over shoulder \\
\hline 9 & $25-27$ & Obese, flat appearance dominates, brisket is heavy \\
\hline
\end{tabular}

${ }^{a}$ Descriptions from Hardin, 1990.

determine a single temperament score (TS) per animal, temperament scores from throughout the experiment were averaged together, and then categorized in two classes (calm animals - TS $<1.5$; excitable animals $-\mathrm{TS} \geq 1.5$ ).

Throughout the study, weather data (dry-bulb temperature, dew-point temperature, solar radiation, wind speed, and wind direction) were collected, using an automated weather station (Vantage Pro, Davis Industries) located in the middle of the four pens.

Ten days prior to initiating the experiments, cattle were preconditioned to observers. During the preconditioning period, two observers spent $1 \mathrm{~h}$ twice daily walking outside pens. Measurements of respiration rate and panting score (Table 3) (Mader and Davis, 2002) were made twice daily ( $0800 \mathrm{~h}$ and $1430 \mathrm{~h}$ ) during six 5-day periods between June 24 and August 9 in 2002, and twelve 3- to 5-day periods between May 20 and August 6 in 2003. On scheduled experimental days, two observers, working independently, each randomly selected five animals in each

Table 2

Temperament scoring system

\begin{tabular}{ll}
\hline Score & $\begin{array}{l}\text { Description of animal's behavior } \\
\text { while confined to a chute }\end{array}$ \\
\hline 1 & Calm, no movement \\
2 & Restless shifting \\
3 & Squirming, occasional shaking of restraint device \\
4 & $\begin{array}{l}\text { Continuous vigorous movement } \\
\text { and shaking of restraint device }\end{array}$ \\
5 & Rearing, twisting or violently struggling \\
\hline
\end{tabular}

${ }^{\mathrm{a}}$ Voisinet et al., 1997. pen to observe. A total of 40 animals were observed each period. For each selected animal, an identification number, standing or lying behavior, panting score, and respiration rate were recorded. Respiration rates were determined by visual observation of flank movement, timing 10 breathes with a stopwatch. Based on weather data recorded prior to and immediately after animal observations, an average ambient temperature was calculated for the analyses.

All animals used in the study were born and raised at the USMARC; therefore a complete health history was available for each individual animal. The disease evaluated in this manuscript was pneumonia. The number of times an animal was diagnosed and treated for pneumonia was aggregated into a single number without regard to date of incident.

Data collected over two summers were compiled into one data set, and then assigned to one of ten temperature categories (TC) based on dry-bulb tem-

Table 3

Description of panting scores

\begin{tabular}{ll}
\hline Score & Description $^{\text {a }}$ \\
\hline 0 & $\begin{array}{l}\text { Normal respiration, } \sim 60 \text { or less breaths/min } \\
1\end{array}$ \\
2 & $\begin{array}{l}\text { Slightly elevated respiration, } 60-90 \text { breaths/min } \\
\text { or small amount of saliva, } 90-120 \text { breaths/min }\end{array}$ \\
3 & $\begin{array}{l}\text { Heavy open-mouthed panting; saliva usually } \\
\text { present, } 120-150 \text { breaths/min }\end{array}$ \\
4 & $\begin{array}{l}\text { Severe open-mouthed panting accompanied } \\
\text { by protruding tongue and excessive salivation }\end{array}$ \\
\hline
\end{tabular}

\footnotetext{
${ }^{a}$ Panting scores were assigned based on visual observation of
} behavior, not on the estimation of respiration rates. 
perature $\left(t_{\mathrm{db}}\right)\left(\mathrm{TC} 1: t_{\mathrm{db}} \leq 12 ;\right.$ TC $2: 12<t_{\mathrm{db}} \leq 15$; TC 3 : $15<t_{\mathrm{db}} \leq 18$; TC $4: 18<t_{\mathrm{db}} \leq 21$; TC $5: 21<t_{\mathrm{db}} \leq 24$; TC 6: $24<t_{\mathrm{db}} \leq 27$; TC 7: $27<t_{\mathrm{db}} \leq 30$; TC $8: 30<t_{\mathrm{db}} \leq 33$; TC 9: $33<t_{\mathrm{db}} \leq 36$; TC 10: $t_{\mathrm{db}}>36$ ).

Analyses were completed to determine if breed, temperature, condition score, health, temperament and/or the interactions of these factors impact the respiration rate or panting score. The data were compiled and analyzed using the following model.

$$
\begin{aligned}
y_{\mathrm{ijklm}}= & \mu+\alpha_{\mathrm{i}}+\beta_{\mathrm{j}}+\delta_{\mathrm{k}}+\gamma_{1}+\kappa_{\mathrm{m}}+\alpha \beta_{\mathrm{ij}}+\alpha \delta_{\mathrm{ik}} \\
& +\alpha \gamma_{\mathrm{il}}+\alpha \kappa_{\mathrm{im}}+\beta \delta_{\mathrm{jk}}+\beta \gamma_{\mathrm{jl}}+\beta \kappa_{\mathrm{jm}}+\delta \gamma_{\mathrm{kl}} \\
& +\delta \kappa_{\mathrm{km}}+\gamma \kappa_{\mathrm{lm}}+\alpha \beta \delta_{\mathrm{ijk}}+\alpha \beta \gamma_{\mathrm{ijl}}+\alpha \beta \kappa_{\mathrm{ijm}} \\
& +\alpha \delta \gamma_{\mathrm{ikl}}+\alpha \delta \kappa_{\mathrm{ikm}}+\alpha \gamma \kappa_{\mathrm{ilm}}+\beta \delta \gamma_{\mathrm{jkl}}+\beta \delta \kappa_{\mathrm{jkm}} \\
& +\beta \gamma \kappa_{\mathrm{jlm}}+\delta \gamma \kappa_{\mathrm{klm}}+\alpha \beta \delta \gamma_{\mathrm{ijkl}}+\alpha \beta \delta \kappa_{\mathrm{ijkm}} \\
& +\alpha \delta \gamma \kappa_{\mathrm{iklm}}+\beta \delta \gamma \kappa_{\mathrm{jklm}}+\alpha \beta \delta \gamma \kappa_{\mathrm{ijklm}}+\varepsilon_{\mathrm{ijklm}}
\end{aligned}
$$

Where: $\mu$ is the overall mean, $\alpha_{i}$ is the effect of the ith breed, $\beta$ is the effect of the jth temperature category, $\delta$ is the effect of the kth finish category, $\gamma$ is the effect of the lth temperament category, $\kappa$ is the effect of the mth number of cases of pneumonia, and $\varepsilon_{\mathrm{ijklm}}$ is the error term. All the interaction terms were included in the initial analysis. A step-down analysis was performed to determine significant effects; all interaction terms that did not significantly contribute to the model $(P>0.10)$ were eliminated until the model contained main effects and only significant interaction terms. The final model for respiration rate is presented below, followed by the final model for panting score.

$$
\begin{aligned}
y_{\mathrm{ijklm}}= & \mu+\alpha_{\mathrm{i}}+\beta_{\mathrm{j}}+\delta_{\mathrm{k}}+\gamma_{1}+\kappa_{\mathrm{m}}+\alpha \beta_{\mathrm{ij}}+\beta \delta_{\mathrm{jk}} \\
& +\beta \gamma_{\mathrm{jl}}+\beta \kappa_{\mathrm{jm}}+\delta \gamma_{\mathrm{kl}}+\alpha \gamma_{\mathrm{il}}+\alpha \beta \delta_{\mathrm{ijk}} \\
& +\alpha \beta \delta \gamma_{\mathrm{ijkl}}+\alpha \beta \delta \gamma \kappa_{\mathrm{ijklm}}+\varepsilon_{\mathrm{ijklm}} \\
y_{\mathrm{ijklm}}= & \mu+\alpha_{\mathrm{i}}+\beta_{\mathrm{j}}+\delta_{\mathrm{k}}+\gamma_{1}+\kappa_{\mathrm{m}}+\beta \gamma_{\mathrm{jl}}+\delta \gamma_{\mathrm{kl}} \\
& +\delta \kappa_{\mathrm{km}}+\alpha \beta \delta_{\mathrm{ijk}}+\beta \delta \gamma_{\mathrm{jkl}}+\alpha \beta \delta \gamma_{\mathrm{ijkl}} \\
& +\alpha \beta \delta \kappa_{\mathrm{ijkm}}+\alpha \beta \delta \kappa_{\mathrm{ijkm}}+\varepsilon_{\mathrm{ijklm}}
\end{aligned}
$$

To investigate certain effects in more detail, analyses were conducted on one or two effects at a time as described below. For simplicity of further analysis, animals treated at least one time for pneumonia were categorized as the treated group, while remaining animals were placed in the untreated group. Animals previously treated for pneumonia were removed from all analyses, except where health history was included.

Differences in respiration rate and panting score at each of the temperature categories were determined by using the following model:

$y_{\mathrm{i}}=\mu+\alpha_{\mathrm{i}}+\varepsilon_{\mathrm{i}}$

where: $\mu$ is the overall mean, $\alpha_{i}$ is the effect of the ith temperature category, and the error term of $\varepsilon_{\mathrm{ij}}$. Least square means procedure was used to determine differences in respiration rate or panting score at each temperature category at the $P<0.05$ level.

Differences in respiration rate and panting score responses among different breeds (Angus, MARC III, Gelbvieh, and Charolais), condition score $(6,7,8,9)$, health (treated and untreated), and temperament (calm and excitable) were tested, using the general linear model procedure in SAS (SAS, 2000) using the following model:

$y_{\mathrm{ij}}=\mu+\alpha_{\mathrm{i}}+\beta_{\mathrm{j}}+\alpha \beta_{\mathrm{ij}}+\varepsilon_{\mathrm{ij}}$

where: $\mu$ is the overall mean, $\alpha_{i}$ is the effect of the ith factor of interest (breed, condition score, etc.), $\beta_{\mathrm{j}}$ is the effect of the $\mathrm{jth}$ temperature category, $\alpha \beta_{\mathrm{ij}}$ is the interaction term of the factor of interest and the temperature category, and the error term of $\varepsilon_{\mathrm{ij}}$. Least square means procedure was used to determine differences in the main effects, and interaction of the main effect and the temperature category at the $P<0.05$ level.

Three additional analyses were conducted using two factors on the Charolais and Angus breeds only. The first analysis investigated breed and health (treated and untreated); the second analysis investigated breed and condition score $(\mathrm{CS}<8$ and $\mathrm{CS} \geq 8$, only); the third analysis investigated breed and temperament $($ calm $<1.5$ and excitable $\geq 1.5)$. These three analyses combined two factors of interest into one risk factor; for example, Angus heifers and had been previously treated for pneumonia were categorized as Risk 1; Charolais heifers and had been previously treated for pneumonia were categorized as Risk 2; Angus heifers and had not been treated for 
pneumonia were categorized as Risk 3; Risk 4 category was assigned to Charolais heifers which had not been treated for pneumonia. The following model was used to analyze the effect of risk category:

$y_{\mathrm{ij}}=\mu+\alpha_{\mathrm{i}}+\beta_{\mathrm{j}}+\alpha \beta_{\mathrm{ij}}+\varepsilon_{\mathrm{ij}}$

where: $\mu$ is the overall mean, $\alpha_{\mathrm{i}}$ is the effect of the ith risk, $\beta_{\mathrm{j}}$ is the effect of the jth temperature category, $\alpha \beta_{\mathrm{ij}}$ is the interaction term of the risk and the temperature category, and the error term of $\varepsilon_{\mathrm{ij}}$. Least square means procedure was used to determine differences in the main effects, and differences in the main effects at each temperature category at the $P<0.05$ level.

The impact of breed, health history, and temperament on the average daily gain was tested, using the general linear model procedure in SAS (SAS, 2000), using the following model:

$$
\begin{aligned}
y_{\mathrm{ij}}= & \mu+\alpha_{\mathrm{i}}+\beta_{\mathrm{j}}+\delta_{\mathrm{k}}+\alpha \beta_{\mathrm{ij}}+\alpha \delta_{\mathrm{ik}}+\beta \delta_{\mathrm{jk}}+\alpha \beta \delta_{\mathrm{ijk}} \\
& +\varepsilon_{\mathrm{ij}}
\end{aligned}
$$

where: $\mu$ is the overall mean, $\alpha_{i}$ is the effect of the ith breed, $\beta$ is the effect of the jth temperament category (calm or excitable), $\delta$ is the effect of the kth health category (treated or untreated), and the error term of $\varepsilon_{\mathrm{ijk}}$. All the interaction terms were included in the initial analysis. A step-down analysis was performed to determine significant effects; all interaction terms that did not significantly contribute to the model $(P>0.10)$ were eliminated until the model contained main effects and only significant interaction terms. The final model is presented below. Least square

Table 4

\begin{tabular}{|c|c|c|}
\hline Effects & Respiration rate $^{\mathrm{a}}$ & Panting score \\
\hline Breed of cattle (breed) & $P<0.0001$ & $P<0.0001$ \\
\hline Temperature category (temperature) & $P<0.0001$ & $P<0.0001$ \\
\hline Finish & $P=0.0014$ & $P=0.2793$ \\
\hline Temperament score (temperament) & $P=0.2226$ & $P=0.6197$ \\
\hline \# of cases of pneumonia (pneumonia) & $P=0.0151$ & $P=0.8454$ \\
\hline Breed $\times$ temperature & $P=0.0006$ & $\mathrm{~N} / \mathrm{A}$ \\
\hline Breed $\times$ finish & $\mathrm{N} / \mathrm{A}$ & $P=0.0583$ \\
\hline Breed $\times$ pneumonia & $P<0.0001$ & $P=0.0099$ \\
\hline Breed $\times$ temperament & N/A & $\mathrm{N} / \mathrm{A}$ \\
\hline Temperature $\times$ finish & $P<0.0001$ & N/A \\
\hline Temperature $\times$ pneumonia & $P<0.0001$ & $P=0.0124$ \\
\hline Temperature $\times$ temperament & $P=0.0725$ & $\mathrm{~N} / \mathrm{A}$ \\
\hline Finish $\times$ pneumonia & $P<0.0001$ & $P=0.0037$ \\
\hline Finish $\times$ temperament & N/A & N/A \\
\hline Pneumonia $\times$ temperament & N/A & N/A \\
\hline Breed $\times$ temperature $\times$ finish & N/A & $P=0.0003$ \\
\hline Breed $\times$ temperature $\times$ pneumonia & $\mathrm{N} / \mathrm{A}$ & $\mathrm{N} / \mathrm{A}$ \\
\hline Breed $\times$ temperature $\times$ temperament & N/A & N/A \\
\hline Breed $\times$ finish $\times$ pneumonia & N/A & N/A \\
\hline Breed $\times$ finish $\times$ temperament & $\mathrm{N} / \mathrm{A}$ & N/A \\
\hline Breed $\times$ pneumonia $\times$ temperament & N/A & N/A \\
\hline Temperature $\times$ finish $\times$ pneumonia & $\mathrm{P}<0.0001$ & $\mathrm{P}=0.0003$ \\
\hline Temperature $\times$ finish $\times$ temperament & $\mathrm{N} / \mathrm{A}$ & $\mathrm{P}=0.0595$ \\
\hline Temperature $\times$ pneumonia $\times$ temperament & N/A & N/A \\
\hline Finish $\times$ pneumonia $\times$ temperament & N/A & N/A \\
\hline Breed $\times$ temperature $\times$ finish $\times$ pneumonia & $\mathrm{N} / \mathrm{A}$ & $\mathrm{N} / \mathrm{A}$ \\
\hline Breed $\times$ finish $\times$ pneumonia $\times$ temperament & N/A & N/A \\
\hline Breed $\times$ temperature $\times$ pneumonia $\times$ temperament & N/A & $P=0.0446$ \\
\hline Breed $\times$ temperature $\times$ finish $0 \times$ temperament & $\mathrm{N} / \mathrm{A}$ & $\mathrm{N} / \mathrm{A}$ \\
\hline Temperature $\times$ finish $\times$ pneumonia $\times$ temperament & N/A & N/A \\
\hline Breed $\times$ temperature $\times$ finish $\times$ pneumonia $\times$ temperament & $P<0.0001$ & $P=0.0023$ \\
\hline
\end{tabular}

Significant effects on cattle respiration rates and panting scores

\footnotetext{
${ }^{a} \mathrm{~N} / \mathrm{A}=$ Effect was not included in the final model due to the lack of significance.
} 
Table 5

Average condition score, temperament, and number of treated animals per breed

\begin{tabular}{llccc}
\hline & Angus & MARC III & Gelbvieh & Charolais \\
\hline Beginning condition score & $19.3 \pm 0.02^{\mathrm{a}}$ & $17.9 \pm 0.02^{\mathrm{b}}$ & $16.0 \pm 0.02^{\mathrm{c}}$ & $16.1 \pm 0.02^{\mathrm{c}}$ \\
Ending condition score & $24.9 \pm 0.02^{\mathrm{a}}$ & $24.0 \pm 0.02^{\mathrm{b}}$ & $22.5 \pm 0.02^{\mathrm{c}}$ & $22.4 \pm 0.02^{\mathrm{c}}$ \\
Average temperament score & $1.28 \pm 0.09^{\mathrm{a}}$ & $1.29 \pm 0.08^{\mathrm{a}}$ & $1.55 \pm 0.08^{\mathrm{c}}$ & $1.60 \pm 0.08^{\mathrm{c}}$ \\
Number of treated animals (total of 64) & $19 \pm 3.2^{\mathrm{a}, \mathrm{b}, \mathrm{c}}$ & $22 \pm 3.2^{\mathrm{b}}$ & $11 \pm 3.2^{\mathrm{cd}}$ & $10 \pm 3.2^{\mathrm{d}}$ \\
\hline
\end{tabular}

$\overline{\mathrm{a}, \mathrm{b}, \mathrm{c}}$ Numbers in a single row with differing superscripts were significantly different $(P>0.05)$.

means were used to determine significant differences in the main effects at the $P<0.05$ level.

$y_{\mathrm{ij}}=\mu+\alpha_{\mathrm{i}}+\beta_{\mathrm{j}}+\delta_{\mathrm{k}}+\varepsilon_{\mathrm{ij}}$

\section{Results and discussion}

The initial analyses (Table 4) have shown that an animal stress level due to heat stress is impacted by a combination of factors, including the interaction of temperature category and all remaining factors of interest (breed, finish, number of cases of pneumonia, and temperament). To further investigate these impacts of different risk factors, individual effects were tested separately, thus overlooking the unbalanced nature of the data (see Table 5).

Environmental conditions and number of points at each temperature category are shown in Table 6 . Respiration rate and panting score increased with temperature category. The increase of respiration rate with temperature is well documented (Brown-Brandl et al., 2003; Eigenberg et al., 2000; Hahn et al., 1997; Mader et al., 1999). Since respiration rate is affected by all weather factors (Eigenberg et al., 2004), others including wind speed, dew-point temperature, and solar radiation should be examined. In the third and ninth temperature category, respiration rate did not seem to increase as expected; upon closer examination, it was found that wind speed increased during those time periods, which could explain this anomaly. Panting score illustrated the threshold temperature of approximately $22{ }^{\circ} \mathrm{C}$; panting scores were not significantly different from 0 until the fourth temperature category $\left(19.4{ }^{\circ} \mathrm{C}\right)$, and showed a significant increase at temperature category $5\left(22.5^{\circ} \mathrm{C}\right)$ (Fig. 1). Eigenberg et al. (2004) found a similar threshold temperature of approximately $25{ }^{\circ} \mathrm{C}$ for respiration rate.

The impact of breed was striking - breed, temperature category, and breed by temperature category all affected respiration rate and panting score $(P<0.0001)$. Angus and MARC III had the highest respiration rate $(94.0 \pm 1.2$ breaths $/ \mathrm{min}$ and $93.4 \pm 1.2$ breaths/min, respectively) and panting score $(0.64 \pm 0.2$ and $0.58 \pm 0.3$, respectively), followed by Gelbvieh (respiration rate $-84.6 \pm 1.0$ breaths $/ \mathrm{min}$; panting score $-0.42 \pm 0.2$ ), then Charolais (respiration rate $-78.1 \pm 1.0$ breaths $/ \mathrm{min}$; panting score $0.35 \pm 0.2$ ). Upon closer evaluation of breed by

Table 6

Average environmental conditions and number of points in each temperature category

\begin{tabular}{|c|c|c|c|c|c|c|}
\hline $\begin{array}{l}\text { Temperature } \\
\text { category }\end{array}$ & $\begin{array}{l}\text { Temperature } \\
\text { range }\left({ }^{\circ} \mathrm{C}\right)\end{array}$ & $N$ & $\begin{array}{l}\text { Dry-bulb temperature } \\
\left({ }^{\circ} \mathrm{C}\right)\end{array}$ & $\begin{array}{l}\text { Dew-point temperature } \\
\left({ }^{\circ} \mathrm{C}\right)\end{array}$ & $\begin{array}{l}\text { Solar radiation } \\
\left(\mathrm{W} / \mathrm{m}^{2}\right)\end{array}$ & $\begin{array}{l}\text { Wind speed } \\
(\mathrm{m} / \mathrm{s})\end{array}$ \\
\hline 1 & $t_{\mathrm{db}} \leq 12$ & 80 & $9.5 \pm 1.5$ & $5.5 \pm 3.1$ & $414 \pm 85$ & $5.0 \pm 0.0$ \\
\hline 2 & $12>t_{\mathrm{db}} \leq 15$ & 360 & $13.9 \pm 0.9$ & $10.7 \pm 3.1$ & $292 \pm 151$ & $4.8 \pm 3.8$ \\
\hline 3 & $15>t_{\mathrm{db}} \leq 18$ & 240 & $16.7 \pm 0.9$ & $13.1 \pm 1.8$ & $331 \pm 128$ & $9.5 \pm 3.5$ \\
\hline 4 & $18>t_{\mathrm{db}} \leq 21$ & 1040 & $19.4 \pm 0.9$ & $14.0 \pm 2.6$ & $422 \pm 223$ & $7.7 \pm 4.4$ \\
\hline 5 & $21>t_{\mathrm{db}} \leq 24$ & 1040 & $22.5 \pm 0.8$ & $17.2 \pm 2.0$ & $360 \pm 137$ & $8.3 \pm 4.7$ \\
\hline 6 & $24>t_{\mathrm{db}} \leq 27$ & 1380 & $25.5 \pm 0.8$ & $16.9 \pm 3.2$ & $471 \pm 205$ & $10.8 \pm 5.7$ \\
\hline 7 & $27>t_{\mathrm{db}} \leq 30$ & 900 & $28.6 \pm 0.8$ & $16.5 \pm 3.3$ & $635 \pm 227$ & $11.0 \pm 5.6$ \\
\hline 8 & $30>t_{\mathrm{db}} \leq 33$ & 800 & $31.7 \pm 0.7$ & $16.5 \pm 4.5$ & $748 \pm 176$ & $9.7 \pm 4.8$ \\
\hline 9 & $33>t_{\mathrm{db}} \leq 36$ & 641 & $34.0 \pm 0.8$ & $18.5 \pm 2.1$ & $823 \pm 64$ & $14.6 \pm 4.2$ \\
\hline 10 & $t_{\mathrm{db}}>36$ & 140 & $37.6 \pm 0.8$ & $14.3 \pm 1.7$ & $681 \pm 108$ & $11.6 \pm 6.5$ \\
\hline
\end{tabular}




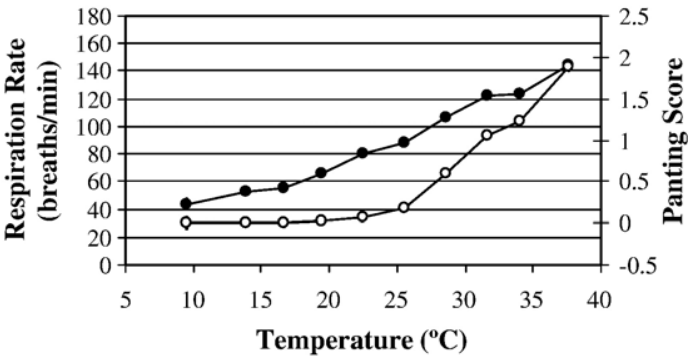

Respiration Rate -o-Panting Score

Fig. 1. The effects of increasing temperature on respiration rate and panting score of feedlot heifers. Error bars represent the standard error associated with each point.

temperature category interaction, it appeared that Charolais responses separated from the group at a fairly low temperature. Charolais' respiration rate was significantly lower than Angus and MARC III respiration rate at temperature category $4\left(19.4{ }^{\circ} \mathrm{C}\right)$, and significantly lower than Gelbvieh at temperature category $5\left(22.5^{\circ} \mathrm{C}\right)$ (Fig. 2a and b). Charolais panting score followed a similar trend, being significantly lower than Angus at temperature category $5\left(22.5^{\circ} \mathrm{C}\right)$, MARC III at temperature category $6\left(25.5^{\circ} \mathrm{C}\right)$, and Gelbvieh at temperature category $7\left(28.6{ }^{\circ} \mathrm{C}\right)$. Gelbvieh separated from the group at temperature category $7\left(28.6{ }^{\circ} \mathrm{C}\right)$. Results seemed logical due to hide color differences, which affect the adsorption of solar radiation. Adsorption of solar radiation from a black-hided animal was 93\%, while the adsorption of light-hided animal was only $27 \%$ (da Silva et al., 2003). The companion paper, BrownBrandl et al., (2006), found that the dark-hided breeds of cattle (Angus, MARC III) had not only higher respiration rate, panting score, and hide surface temperatures, but also adjusted their behavior more under hot conditions compared to cool conditions than the light-hided breeds of cattle (Gelbvieh, Charolais).

Condition score, health status, and temperament contain anecdotal evidence to suggest these factors influence responses to stress; however, there are few refereed papers documenting their effect. Animals with higher condition scores had higher respiration rate and panting score $(P>0.05)$. Animals with condition score of six had the lowest respiration rate $(78.2 \pm 1.0$ breaths $/ \mathrm{min})$ and panting score $(0.30 \pm$ 0.02). Animals with condition score of seven had the next lowest respiration rate $(85.3 \pm 0.7$ breaths $/ \mathrm{min})$ and panting score $(0.44 \pm 0.01)$, followed by condition score of eight and nine (respiration rate $92.3 \pm 0.8$ breaths $/ \mathrm{min}, 96.3 \pm 1.6$ breaths $/ \mathrm{min}$ and panting score $-0.58 \pm 0.02,0.66 \pm 0.04$, respectively). Fig. $3 a$ and $b$ show responses of animals with differing condition score as temperature increases. Animals with condition score of six started separating from the other groups at temperature category 5 $\left(22.5{ }^{\circ} \mathrm{C}\right)$. At temperature category $6\left(25.5{ }^{\circ} \mathrm{C}\right)$, effects of higher condition scores began to separate out. This also supports a threshold temperature of approximately $25{ }^{\circ} \mathrm{C}$ as found by Eigenberg et al. (2004). At higher temperatures, points appear to come together; this may be due to limited number of observations at higher temperature categories.

Animals treated for respiratory pneumonia any time from birth to slaughter (treated) had higher

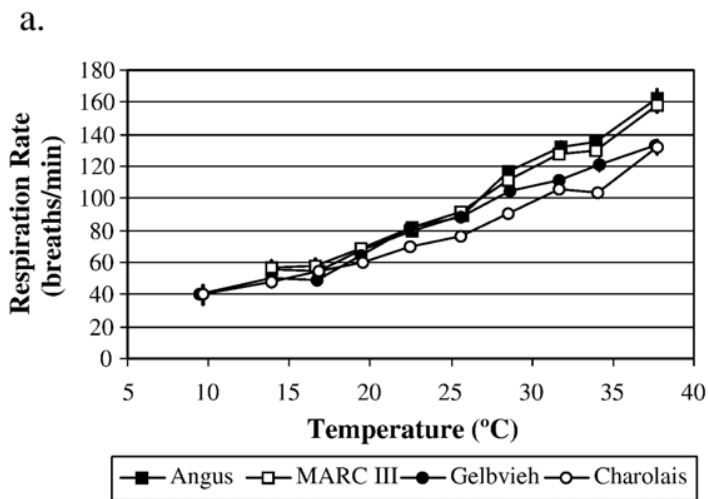

b.

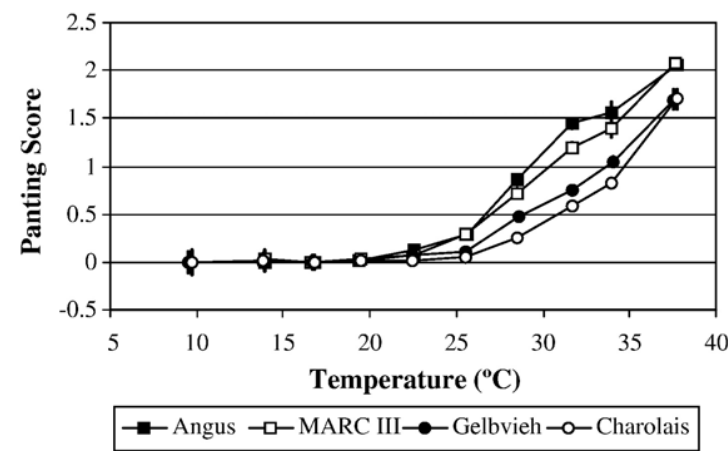

Fig. 2. Respiration rate (a) and panting score (b) response differences between feedlot heifers of four differing breeds (Angus - black; MARC III - dark-red; Gelbvieh - tan; and Charolais - white). Error bars represent the standard error associated with each point. 
a.

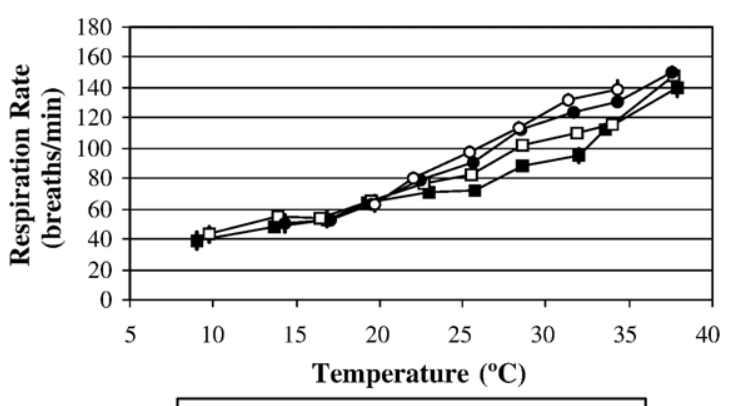

Condition Score $\rightarrow-6 \multimap \square-7 \multimap-8 \multimap 9$

b.

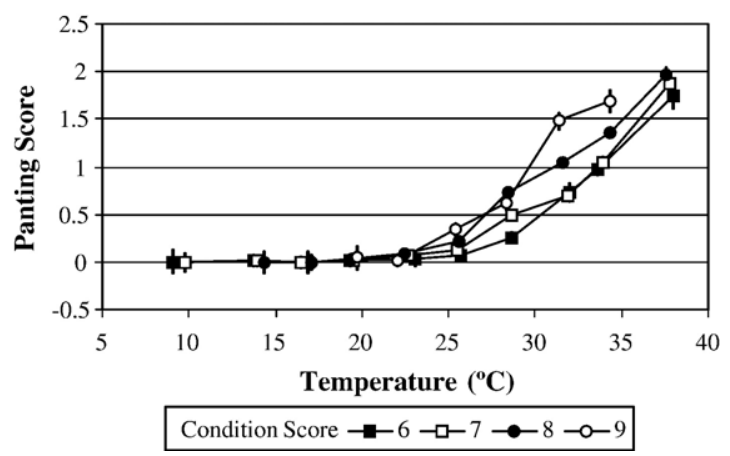

Fig. 3. Respiration rate (a) and panting score (b) response differences between feedlot heifers of four different condition scores. Error bars represent the standard error associated with each point.

respiration rate $(92.1 \pm 0.9)$ and panting score $(0.57 \pm 0.02)$ than those never diagnosed with respiratory pneumonia (untreated) (respiration rate $-86.7 \pm$ 0.6 breaths/min; panting score $-0.48 \pm 0.01$ ). Treated animals were affected more by increasing temperature than untreated animals $(P<0.0001)$ (Fig. 4). Treated animals had a significantly higher respiration rate from temperature category $5\left(22.5^{\circ} \mathrm{C}\right)$ through temperature category $9\left(34.0{ }^{\circ} \mathrm{C}\right)$. The panting score followed a similar trend, but differences did not appear until higher temperatures (temperature category $7-28.6{ }^{\circ} \mathrm{C}$ ). This was a very significant finding - it suggested that early respiratory illness has a lasting impact. An analysis to help describe that lasting impact could not be performed, due to low numbers of treated animals. These results also suggest that the animals that were treated for pneumonia had lasting effects such as lung lesions (a result of scar tissue forming in the lungs due to a respiratory disease). Buhman et al. (2000) found

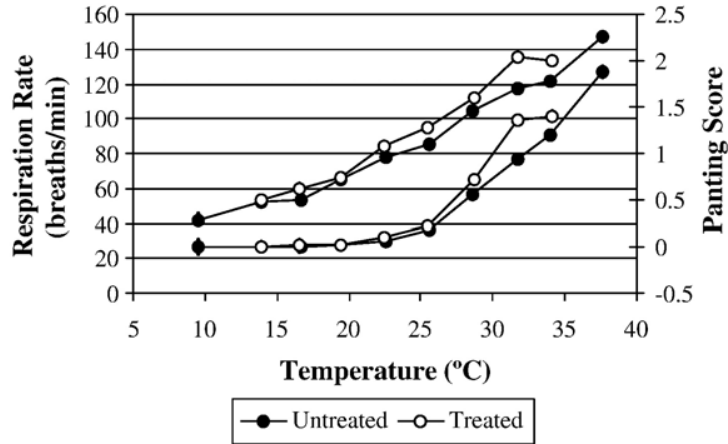

Fig. 4. Respiration rate and panting score response differences between feedlot heifers diagnosed and treated for respiratory pneumonia any time from birth to slaughter (treated), and those never diagnosed with respiratory pneumonia (untreated). Error bars represent the standard error associated with each point.

only fair agreement between treated animals and those with lung lesions, which does not seem to be the case with these animals, but is likely the case in a typical feedlot herd.

Calm heifers $(\mathrm{TS}<1.5)$ had lower respiration rates $(85.4 \pm 0.6$ breaths $/ \mathrm{min})$ but similar panting scores $(0.49 \pm 0.02)$ compared to excitable heifers (respiration rate $-88.4 \pm 0.8$ breaths $/ \mathrm{min}$; panting score $0.48 \pm 0.01)$. Although temperament appeared to have a smaller impact than other factors investigated, there were significant differences (Fig. 5). Calm heifers had significantly lower respiration rate in all temperature categories above $5\left(22.5{ }^{\circ} \mathrm{C}\right)$, except for temperature category 8 where the two categories were similar.

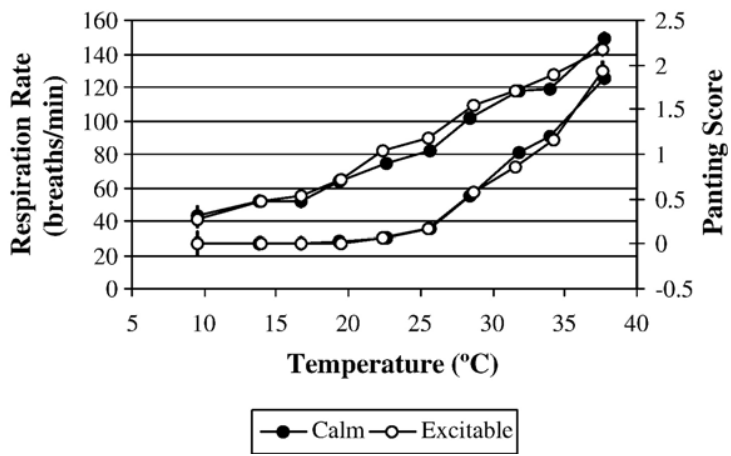

Fig. 5. Respiration rate and panting score response differences between feedlot heifers with temperament scores less than or equal to 1.5 (calm), or greater than 1.5 (excitable). Error bars represent the standard error associated with each point 


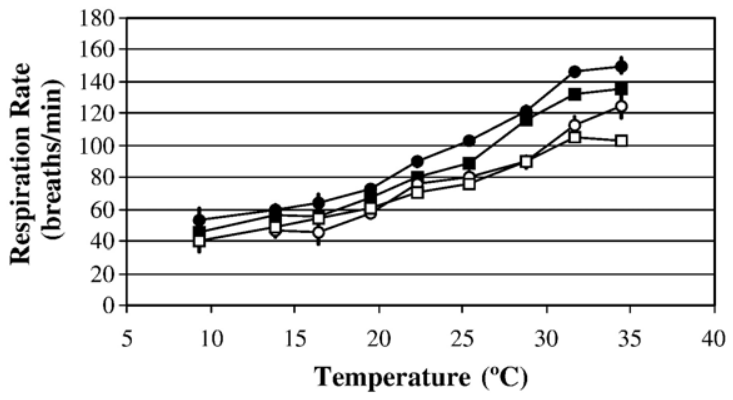

$\begin{array}{ll}\longrightarrow-\text { Angus and Treated } & \rightarrow-\text { Angus and Untreated } \\ -\infty-\text { Charolais and Treated } & \rightarrow-\text { Charolais and Untreated }\end{array}$

Fig. 6. Respiration rate responses of Angus and Charolais heifers that were either diagnosed and treated for respiratory pneumonia any time from birth to slaughter (treated), or those never diagnosed with respiratory pneumonia (untreated). Error bars represent the standard error associated with each point.

When multiple factors were compared, effects of each factor remained consistent (Figs. 6-8), and the effects appeared to be additive. All comparisons between categories in this section were made at temperatures greater than $25.5{ }^{\circ} \mathrm{C}$ (temperature category 6). Fig. 6 illustrates the combined effects of health (as measured by cases of pneumonia) and breed (only Charolais and Angus). This combined analysis revealed the impact of breed as follows: Angus heifers had $25.4 \%$ higher respiration rates than Charolais. Heifers treated for pneumonia had $10.5 \%$ higher respiration rates than untreated. When these two categories were combined, treated Angus heifers

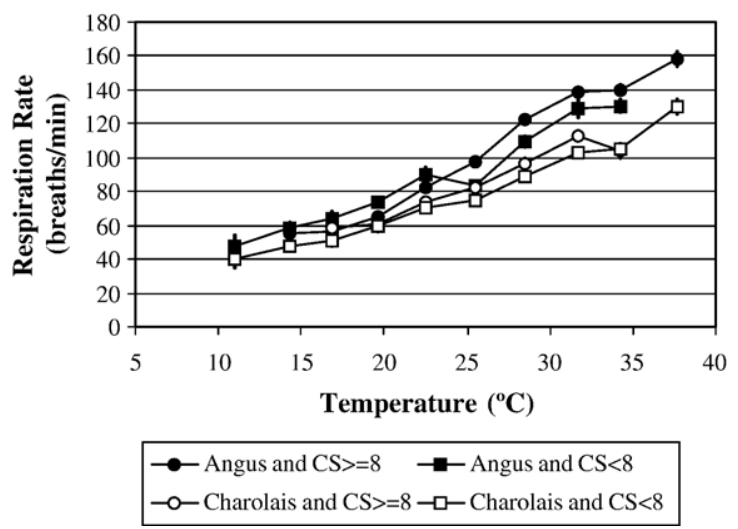

Fig. 7. Respiration rate responses of Angus and Charolais heifers that either had a condition score (CS) greater than or equal to 8 , or less than 8 . Error bars represent the standard error associated with each point.

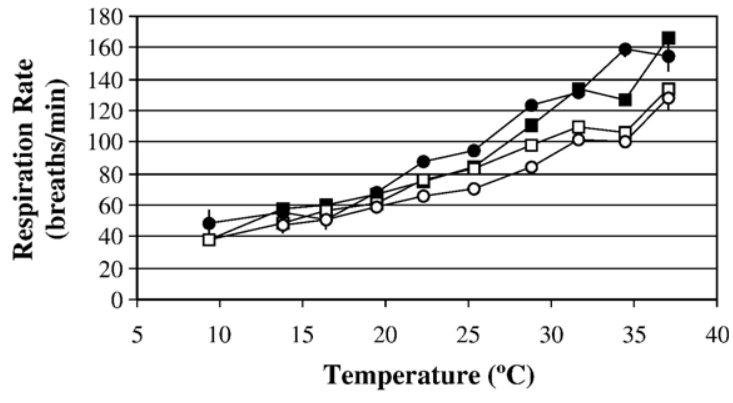

$\longrightarrow$ - Angus and Excitable $\rightarrow-$ Angus and Calm
$\rightarrow \square$ Charolais and Excitable $\longrightarrow$ - Charolais and Calm

Fig. 8. Respiration rate responses of Angus and Charolais heifers that either had a temperament score of less than or equal to 1.5 (calm) or greater than 1.5 (excitable). Error bars represent the standard error associated with each point.

had $38.7 \%$ higher respiration rates than untreated Charolais. The difference between treated and untreated heifers averaged 9.3\% (Angus - 10.0\%, Charolais $-8.6 \%$ ), which matches overall health effect of $10.5 \%$ analyzed above. A similar agreement occurred with breed effect; the difference between treated Angus and Charolais heifers was 27.7\%, and in untreated Angus and Charolais heifers it was $26.0 \%$.

A similar comparison was completed using condition score and breed (Charolais and Angus only). For this comparison, condition scores greater than or equal to eight were grouped together (finished), and condition score less than eight were in another group (lean) (Fig. 7). All comparisons between categories in this section were made at temperatures greater than $25.5{ }^{\circ} \mathrm{C}$ (temperature category 6). The effects of condition score and breed appeared to be additive (Fig. 7). Finished Angus heifers had a $31.6 \%$ higher respiration rate than a lean Charolais. Overall, finished animals had 6.8\% higher respiration rate than lean animals. This is slightly less than was found in the condition score analysis $(11.4 \%$ between condition score 6 and 7 ; $11.4 \%$ between condition score 7 and $8 ; 5.3 \%$ between condition score 8 and 9). Finished Angus had $23.6 \%$ higher respiration rates than finished Charolais, which is similar to the difference found in lean heifers $(22.8 \%)$, which is in agreement with the breed analysis. 
The final comparison of this type was completed using temperament score and breed (Charolais and Angus only). Temperament scores were divided into two categories as done in previous analyses (calm temperament score $<1.5$; excitable - temperament score $\geq 1.5$ ) (Fig. 8). Excitable Angus heifers had a $36.6 \%$ higher respiration rate than the calm Charolais heifers. Excitable heifers had about an 8.0\% increase in respiration rate compared to the calm heifers. This is a substantially larger difference than was found in the temperament analysis. The Angus heifers had a $20.8 \%$ higher respiration rate than the Charolais heifers.

These risk factors not only impact apparent stress levels, but also average daily gain. Breed $(P=$ $0.0075)$, health history ( $P=0.0454)$, and temperament ( $P=0.0017)$ had effects on average daily gain over the summer time grow-out period. None of the interaction effects were significant $(P>0.2)$. The Charolais heifers had significantly higher gain $(1.60 \pm 0.04 \mathrm{~kg} /$ day $)$ than the other three breeds $(P<0.01)$ (Angus $-1.45 \pm 0.04 \mathrm{~kg} / \mathrm{day} ;$ MARC III $1.46 \pm 0.04 \mathrm{~kg} /$ day; Gelbvieh $-1.49 \pm 0.04 \mathrm{~kg} /$ day; $N=64$ for all breeds). While breed is confounded in these differences in gain, there is some evidence that stress level had an impact as well. There were no significant differences between the other three breeds $(P>0.3)$. This seems to be logical because the Charolais heifers were significantly less stressed than the other three breeds at temperatures above $19.5^{\circ} \mathrm{C}$. The Gelbvieh heifers were only significantly less stressed at temperatures above $28.6{ }^{\circ} \mathrm{C}$, and there was no significant difference in stress level between the Angus and MARC III heifers. The MARC III and Angus heifers were able to compensate for approximately 20 additional days (22 days - 2002; 18 days 2003) of stress (above $28.6{ }^{\circ} \mathrm{C}$ ) to maintain a gain similar to the Gelbvieh heifers. However, the animals could not compensate for approximately 49 days of additional stress above $19.5{ }^{\circ} \mathrm{C}$ (44 days - 2002; 54 days -2003 ) to maintain a gain similar to the Charolais.

The health history significantly impacted average daily gain $(P=0.0454)$; heifers that had never been treated for pneumonia had a gain of $1.54 \pm 0.02 \mathrm{~kg} /$ day $(N=194)$, compared to a gain of $1.46 \pm 0.04 \mathrm{~kg} /$ day $(N=62)$ for heifers that had been treated. Similar results have been reported by Wittum et al. (1996), and Donovan et al. (1998). Donovan et al. (1998) found that early pneumonia (before 6 months of age) significantly reduced total weight gain through 14 months. Wittum et al. (1996) found that cattle with lung lesions (found at slaughter) were associated with a reduction in daily gain.

Temperament also had a significant impact $(P=0.0017)$ despite a relatively minor increase in stress level. Calm heifers had a higher gain $(1.56 \pm 0.03 \mathrm{~kg} /$ day; $N=140)$, compared to excitable heifers $(1.44 \pm 0.03 \mathrm{~kg} /$ day; $N=116)$. This suggests that temperament alone could have an impact on gain, and not just the secondary effect of stress level. Voisinet et al. (1997) found similar results; they concluded cattle that were quieter and calmer during handling had higher average daily gains than cattle that became agitated during handling.

\section{Conclusions}

This study determined that temperature, breed, condition score, health history (history of pneumonia), and temperament had effects on both respiration rate and panting score, the two parameters used in this study to measure heat stress. Black and dark-red animals (Angus and MARC III) were similar in their respiration rate responses to increasing temperature. However, dark animals (both Angus and MARC III) had an average respiration rate that was $10.6 \%$ higher than Gelbvieh heifers, and $25.4 \%$ higher than the Charolais heifers. Gelbvieh heifers had a $10.3 \%$ higher average respiration rate than the Charolais heifers. This increase in respiration rate indicates a larger imbalance in the ratio of heat loss to heat production/gain in the animals, thus indicating an increase in stress. Heifers with higher condition scores had significantly higher respiration rates than heifers with lower condition scores. Animals which were treated for pneumonia between birth and slaughter averaged $10.5 \%$ higher respiration rates under stressful conditions than untreated animals; the difference between the two groups was evident at temperatures above $22.5{ }^{\circ} \mathrm{C}$. Temperament had a small effect; excitable heifers had a 3.2\% increase in respiration rate under stressful conditions, compared to calm heifers. Panting scores showed a similar trend in all factors except temperament, where no difference was found. 
In addition to the physiological indicators of increased stress, there were impacts on average daily gain. Breed, temperament, and previous cases of pneumonia all significantly affected average daily gain. Charolais heifers gained significantly more than any of the other breeds, possibly due to the lower stress level during approximately 49 days in the summer. Calm cattle $(1.56 \mathrm{~kg} /$ day $)$ gained significantly more than excitable cattle $(1.44 \mathrm{~kg} /$ day $)$. Cattle previously treated for pneumonia grew significantly slower $(1.46 \mathrm{~kg} /$ day), compared to $1.54 \mathrm{~kg}$ /day for untreated animals.

Several researchers have reported that respiration rate is a good indicator of stress (Brown-Brandl et al., 2005b; Gaughan et al., 2000; Hahn et al., 1997). Results of this study illustrate sensitivity of respiration rate. While a single measurement of respiration rate would not indicate if an animal is sick, knowing condition score, breed (color), health history, and temperament, a producer could determine which animals are at higher risk of suffering production losses under heat stress conditions, and could manage those animals accordingly.

\section{Acknowledgements}

The authors would like to thank Tanner Augustin, Todd Boman, Andrea Finzel, John Holman, Dan Marintzer, Diane Purcell, and Krystal Zimmerman for their help in collecting data, and Elda Patton for the help in the preparation of this manuscript.

\section{References}

Brown-Brandl, T.M., Eigenberg, R.A., Hahn, G.L., Nienaber, J.A., Mader, T.L., Spiers, D.E., Parkhurst, A.M., 2005a. Analyses of thermoregulatory responses of feeder cattle exposed to simulated heat waves. Int. J. Biometeorol. 49, 285-296.

Brown-Brandl, T.M., Eigenberg, R.E., Nienaber, J.A., Hahn, G.L., 2005b. Dynamic response indicators of heat stress in shaded and non-shaded feedlot cattle: Part 1. Analyses of indicators. Biosyst. Eng. 90, 451-462.

Brown-Brandl, T.M., Nienaber, J.A., Eigenberg, R.A., Hahn, G.L., Freetly, H.C., 2003. Thermoregulatory responses of feeder cattle. J. Therm. Biol. 28, 149-157.

Brown-Brandl, T.M., Nienaber, J.A., Eigenberg, R.A., Mader, T.L., Morrow, J.L., Dailey, J.W., 2006. Comparison of heat tolerance of feedlot heifers of different breeds. Livest. Prod. Sci. 105, 19-26.

Buhman, M.J., Perino, L.J., Galyean, M.L., Wittum, T.E., Montgomery, T.H., Swingle, R.S., 2000. Association between changes in eating and drinking behaviors and respiratory tract disease in newly arrived calves at a feedlot. Am. J. Vet. Res. 61 (10), 1163-1168.

Busby, D., Loy, D., 1996. Heat Stress in Feedlot Cattle: Producer Survey Results. Beef Research Report. A.S. Leaflet R1348. Iowa State University, Ames, IA.

da Silva, R.G., La Scala, N. Jr., Tonhati, H., 2003. Radiative properties of the skin and haircoat of cattle and other animals. Trans. ASAE 46, 913-918.

Donovan, G.A., Dohoo, J.R., Montgomery, D.M., Bennett, F.L., 1998. Calf and disease factors affecting growth in female Holstein calves in Florida U.S.A. Prev. Vet. Med. 33, 1-10.

Eigenberg, R.A., Hahn, G.L., Nienaber, J.A., Brown-Brandl, T.M., Spiers, D., 2000. Development of a new respiration rate monitor for cattle. Trans. ASAE 43, 723-728.

Eigenberg, R.A., Brown-Brandl, T.M., Nienaber, J.A., Hahn, G.L., 2002. Dynamic response of feedlot cattle to shade and no-shade. Paper No. 024050. ASAE, St. Joseph, Mich.

Eigenberg, R.A., Brown-Brandl, T.M., Nienaber, J.A., 2004. Development of a livestock safety monitor for cattle. Paper No. 032338. ASAE, St Joseph, Mich.

Gaughan, J.B., Holt, S.M., Hahn, G.L., Mader, T.L., Eigenberg, R.A., 2000. Respiration rate - is it a good measure of heat stress in cattle? J. Anim. Sci. 13, 329-332.

Hahn, G.L., 1999. Dynamic responses of cattle to thermal heat loads. J. Anim. Sci. 77, 10-20.

Hahn, G.L., Mader, T.L., 1997. Heat waves in relation to thermoregulation, feeding behavior and mortality of feedlot cattle. Proc., 5th Int. Livest. Environ. Symp., vol. I. ASAE, SP01-97, St. Joseph, Mich, pp. 563-571.

Hahn, G.L., Parkhurst, A.M., Gaughan, J.B., 1997. Cattle respiration rate as a function of ambient temperature. Paper No. MC97121. ASAE, St. Joseph, Mich.

Hardin, R., 1990. Using body condition scoring in beef cattle management. Circular 817. University of Georgia College of Agricultural and Environmental Sciences and the U.S. Department of Agriculture.

Hungerford, L.L., Buhman, J.B., Dewell, R.D., Mader, T.L., Griffin, D., Smith, D.R., Nienaber, J.A., 2000. Investigation of heat stress mortality in four midwest feedlots. Int. Symp. on Vet. Epi. and Econ., No. 616, 430-433 (Breckenridge, Colorado).

Mader, T.L., Davis, M.S., 2002. Wind speed and solar radiation corrections for the temperature-humidity index. American Meteorological Society. 15th Conf. Biomet. and Aerobiol, Joint with 16th Int. Cong. on Biomet.

Mader, T.L., Dahlquist, J.M., Hahn, G.L., Gaughan, J.B., 1999. Shade and wind barrier effects on summertime feedlot cattle performance. J. Anim. Sci. 77, 2065-2072.

Mader, T.L., Hungerford, L.L., Nienaber, J.A., Buhman, M.J., Davis, M.S., Hahn, G.L., Cerkoney, W.M., Holt, S.M., 2001. Heat stress mortality in midwest feedlots. J. Anim. Sci. 79 (Suppl. 2), 2. 
SAS User's Guide. Version 8. SAS Institute, Inc., Cary, NC.

Voisinet, B.D., Grandin, T., Tatum, J.D., O’Connor, S.F., Struthers, J.J., 1997. Feedlot cattle with calm temperaments have higher average daily gains than cattle with excitable temperaments. J. Anim. Sci. 75, 892-896.

Wittum, T.E., Woollen, N.E., Littledike, E.T., Perino, L.J., 1996. Relationships among treatment for respiratory tract disease, pulmonary lesions evident at slaughter, and rate of weight gain in feedlot cattle. J. Am. Vet. Med. Assoc. 209, 814-818.

Young, B.A., Hall, A., 1993. Heat load in cattle in the Australian environment. In: Coombes , R. (Ed.), Australian Beef. Morescope Publishing, S. Melbourne, Australia, pp. 143-148. 